\title{
Developing a CALS/EC engine of the ELECTROPIA in Korea
}

\author{
Sounghie Kim, Donghoon Lee, Kijin, Jang \\ Korea Advanced institute of Science and Technology, Seoul, Korea \\ Choong-Hwa Lee \\ Daewoo Information Systems Co., Ltd., Seoul, Korea
}

\begin{abstract}
The ELECTROPIA is a CALS/EC engine developed by the Korea CALS/EC Association composed of the government, several universities, and many small and big companies in Korea, in order to develop and procure standard-public-parts, support electronic commerce, and make use of Internet shopping mall and technical information owned in common.

This paper will present what is the ELECTROPIA and it's subsystems. The ELECTROPIA has four principal subsystems. The first subsystem is the Electronic Tendering System(ELECTROPIA-ETS) which assists those who want electronic transfer globally. The second is the Technical Information System(ELECTROPIA-TIS) which makes each company work together by owning technical information companies especially between small and big companies in Korea. The third is the Customer Service System(ELECTROPIA-CSS) which enables joint service to customers using an electronic manual among companies. Finally, the last one is the Electronic Shopping Plaza(ELECTROPIA-ESP) which provides a shopping mall to any companies whoever want to sell their products through the Internet.
\end{abstract}

\section{Introduction}

The situation in today's manufacturing sector is very competitive. Enterprises are faced with various advanced technologies and a wide spectrum of product demands. In order to maintain it's current position as the pre-emptive competitor in the world, and overcome current economic disaster Korea's manufacturers must have an efficient and integrated application to support their products over the entire life cycle.

CALS(Commerce At Light Speed) is a global strategy to further enterprise integration through the streamlining of business processes and the application of standards and technologies for the development, exchange, and use of business and technical information[1]. In recent years, "the CALS strategy" just as NIIP(National Industrial Infrastructure Protocols) in U.S.A. and MATIC(MAnufacturing Technology supported by advanced and integrated Information system through international Cooperation ) in Japan has become a major factor in the field of implementing advanced information infrastructures in many kinds of organization worldwide. Especially, MATIC is a futureoriented strategy for five years which has been initiated since 1994 by the Center of International Cooperation for Computerization (CICC) under the mandate of Ministry of Internation al Trade and Industry (MITI) in Japan[2]. The countries participate in the project are China, Indonesia, Malaysia, Singapore, and Thailand except Korea.

Activities related CALS have been continuing for several years in Korea since 1990. At the beginning the activities were only limited in CALS knowledge understanding and standards application. In 1996, we launched the ELECTROPIA, which is the name of a CALS, and EC(electronic commerce) engine in order to innovate our traditional business behavior and also the name of it's developing team in Korea. The team of ELECTROPIA which is one of the business units of the Korea CALS/EC Association and the Korea CALS/EC Technology Association in Korea.

At the beginning, the purpose of developing the ELECTROPIA was for electronic and information \& communication business domain. Nowadays, it is for all business domains. The mission of ELECTROPIA is a full implementation of electronic commerce using CALS technology to be able to use all business domains. It's objective contains several activities : Developing and procurement of standard public parts, using shopping plaza, integrating procurement and manufacturing sales, sharing technical information electronically to develop new product, producing standard environment for small and medium companies. 〈Table1> shows several benefits of developing ELECTROPIA. 


\begin{tabular}{|l|l|}
\hline \multicolumn{1}{|c|}{ Subject } & Benefits \\
\hline government & global sorcing, openness, deregulation, \\
\hline big company & cost reduction using common product and global sourcing \\
\hline small company & $\begin{array}{l}\text { fast delivery, enhancing opportunity of selling product and developing new } \\
\text { product, specializing }\end{array}$ \\
\hline customer & easy to buy, many alternatives, low price \\
\hline
\end{tabular}

Table 1 Benefits of developing ELECTROPIA

\section{CALS and Electronic Commerce}

\subsection{CALS acronyms}

CALS is Commerce At Light Speed, or CALS, is a strategy which combiness automation and integration of information and integration of information in order to help organizations do more, better, faster, and at less cost

The CALS acronym has evolved over time. In 1985, CALS began as "Computer Aided Logistic Support", defined as a strtegy for transitioning from paper-based weapon system acquisition and support processes of an integrated and automated environment. As the strategy evolved, by 1988 the name expanded to include acquisition, becoming "Computer-aided Acquisition and Lositic Support" In 1993, the definition of the acronym was changed once again to "Continuous Acquisition and Life-cycle Support". This change was meant to reflect the fact that CALS is really about information and process improvement, and that both are continuous[3].

In the past few years, there has been an esplosion of online commercial activity enabled by the Internet and World Wide Web(WWW).

Nowadays, CALS is called "Commerce At Light Speed". CALS is one of the strategy of electronic commerce(EC)

Broadly defined, EC is a modern business methodology that addresses the needs of organizations, merchants, and consumers to cut costs while improving the quality of goods and services, and increasing the speed of service delivery. The term also applies to the use of computer networks to search and retrieve information in support of human and corporate decisionmaking. More commonly, EC is associated with the buying and selling of information, products, and services via computer networks today and in the future via any one of the myriad of networks that make up the Information Superhighway[4].

\subsection{Electronic Markets}

Electronic Markets are the foundation of electronic commerce. They potentially encompass all of the applications decussed above. An electronic marketplace is an inter organizational information system that allows the participation buyers and sellers to exchange information about prices and product offerings. The firm operating the system is referred to as the intermediary, which may be a market participant- a buyer or seller, an independent third-party, or a multifirm consortium[5]. Electronic Markets provide an electronic, or online, method to facilitate transactions between buyers and sellers that potentially provides support for all of the steps in the entire order fulfillment process.

\subsection{Three view of the Web}

Gina Colarelli O'Connor and Bob O'Keefe[6] say that we consider three perspectives for assessing the role and use of the Web.

A number of authors $[7,8]$ have chosen to view the Web as a form of inter-organizational IS(IOS). They say that commercial use of the Web exhibits many of the traits of IOS(such that benefits must be shared for the IOS to be successful) and some of the strategic advantages(such as a reduction in the importance of physical location)

Second perspective is to consider the Web as a flobal Information System(IS) architecture. Since any computer can, in effect, be connected to any other, companies can build globally distributed Intranets based 
upon Web technology. Suppliers and customers can be included in some aspects of the system, similar to IOS, but typically the provider of the Web- based system integrates suppliers and customers in a way that is dependent upon their use of the system as desired. As Lu and Song[9] discuss, the notion of IOS does not fully translate to systems where users interact with organizations.

Our position is that understanding the development and success of such 'extra organizational systems ' can be aided by taking a marketing perspective.

Using a marketing perspective, we can identify the strategic factors associated with entering and supplying a market. While strategic approaches such as value-chain [10] analysis can be appropriate for determining the survival strategy of an organization, this does not address the competitive advantage of operating in any particular market medium.

\section{The Organization for ELECTROPIA in Korea}

Since the introduction of CALS in Korea in the earlier 1990's, strategic necessity and domestic promotion of CALS were spread in the wide spectrum of government and many small and big companies. The world is moving fast forward information-intensive society in 21st Century as the competition of developing high technology and structuring an advanced information infrastructure is getting severer beyond bo rders and times.

In Korea, such as CALS started in the Unite States, there was and initial CALS study in the militery sector . from the late 1980s, Korean industries have faced unprecedented challeges in the global market mainly due to rising wages and increasing cargo traffic congestion. To face the challenge, Korean government and enterprises have been putting substantial effort in the using of information technologies of their business processing operations. In this regard, EDI has attained a global presence since the early 90 's and has settled down as a predominant methodology in automating and facilitating intercompany business processing.

The Korea CALS/EC Association and the Korea CALS/EC Technology Association are assured that the success in international competition depends on the degree of information-intensiveness. As I mentioned earlier, ELECTROPIA team is a part the Korea CALS/EC Association and Korea CALS/EC Technology Association. The ELECTROPIA team consists of four major electronic companies - SAMSUNG electronics, DAEWOO electronics, LG Elec tronics, HYUNDAI Electronics- and four major SI companies - SAMSUNG Data Systems, DAEWOO Information, LG-EDS systems, HYUNDAI Information Technology. The mission of the CALS/EC Association and the CALS/EC Technology Association is to build up standardization system for CALS implementation, to plan and develop joint programs for the be nefits of members, to establish technical cooperation system and commercial transaction via CALS networks, and to rear CALS experts and specialists.

\section{ELECTROPIA Pilot system}

The ELECTROPIA is consisted of four principal subsystems. The first subsystem is the Electronic Tendering System(ELECTROPIA-ETS) which assists those who want electronic transfer globally. The second is the Technical Information System(ELECTROPIATIS) which makes each company work together by owning technical information especially between small and big companies in korea. The third is the Customer Service System(ELECTROPIA-CSS) which enables joint service to customers using a electronic manual among companies. Finally, the last one is the Electronic Shopping Plaza(ELECTROPIA-ESP) which provides a shopping mall to any companies whoever want to sell their products through the Internet.

The current electronic commerce projections do not clearly distinguish between expectations for business-tobusiness and business to consumer segments of the market. The emerging Internet retail systems are based on an individual with a web browser making a single purchase. But business to business transactions have traditionally involved dophisticated mainframe and EDIbased systems designed for batch processing of large transaction volumes. It is this business to business marketplace that is often omitted or misunderstood in the myriad discussions about the future of the electronic revolution[11].

The ELECTROPIA is grouped two categories. One is business to business system that has the Electronic Tendering System and the Technical Information System, the other is the Customer Service System, and the Electronic Shopping Plaza.

$<$ Figure 1> shows the structure of the ELECTROPIA system. Several star mark in <figure1> is a signal of being under-construction. 


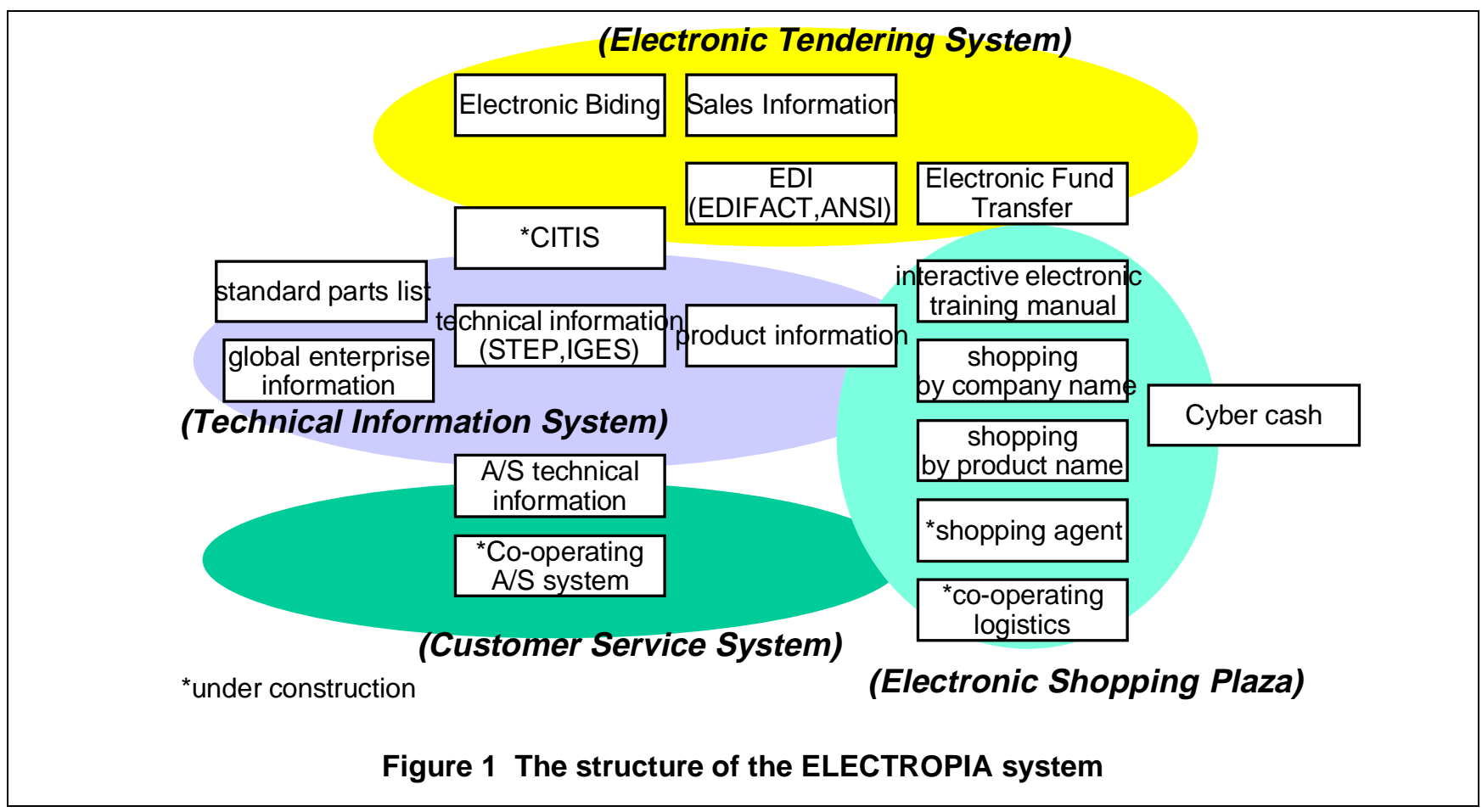

\subsection{ELECTROPIA - ETS(Electronic Tendering System )}

We have developed the Electronic Tendering System as the name of ELECTROPIA-ETS to assists those who want electronic transfer globally.

Separate ordering, and technical information is delivered from different manufacturers. Even in such situation, the purchaser can freely manipulate and utilize the information without knowing who created the data, by sharing the data in a standard format. In order to establishing these, the following was implemented

- The development of database and support tools for the product's parts information

- The development standardization of the product's parts.

- Adding value to parts information created by parts' makers

- The exchange of information among organizations globally.
We grouped two categories as strategic parts and commodidity parts to make databse of parts. Commodity parts are to store the database for ELECTROPIA - ETS. Strategic parts were not disclosed for this purpose, because most of companies thought them core-competance of their business.

<Figure 2> shows strategic parts and commodidity parts.

Especially, it was very important to develop standardization of parts in order to share it 's information among companies. We have created new standards of common parts since the beginging of the project. In addition, we used meta-standardization method .

The ELECTROPIA used Meta-Standardization Method in order to interchange different code of products' part of each company. Meta-Standardziaton Method is that we creat new standards in advance, then interchange each code of prducts ' part through new standards named Meta Standard by autometically. Without this method each company has to invest not in creating new standards, but in fitting new standards. 

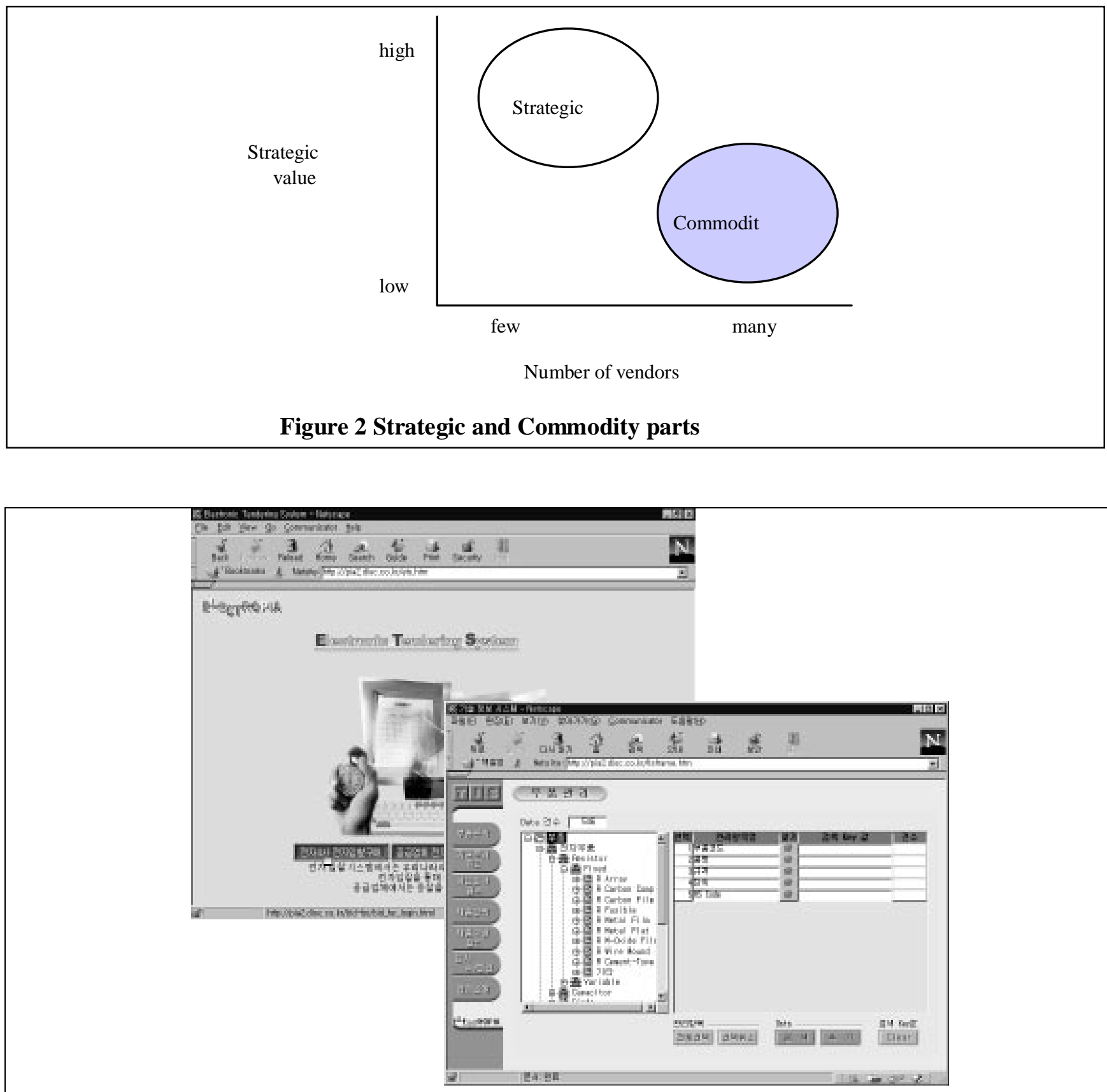

Figure 3 ELECTROPIA-ETS 


\subsection{ELECTROPIA - TIS(Technical Information System)}

We have developed the Technical Information System as the name of ELECTROPIA-TIS to make each company work together by owning technical information especially between small and big companies.
ELECTROPIA-TIS is

- to share information of product development between big companies and small companies.

- to use concurent engineering for integration of design and production

- to integrate data of technology information.

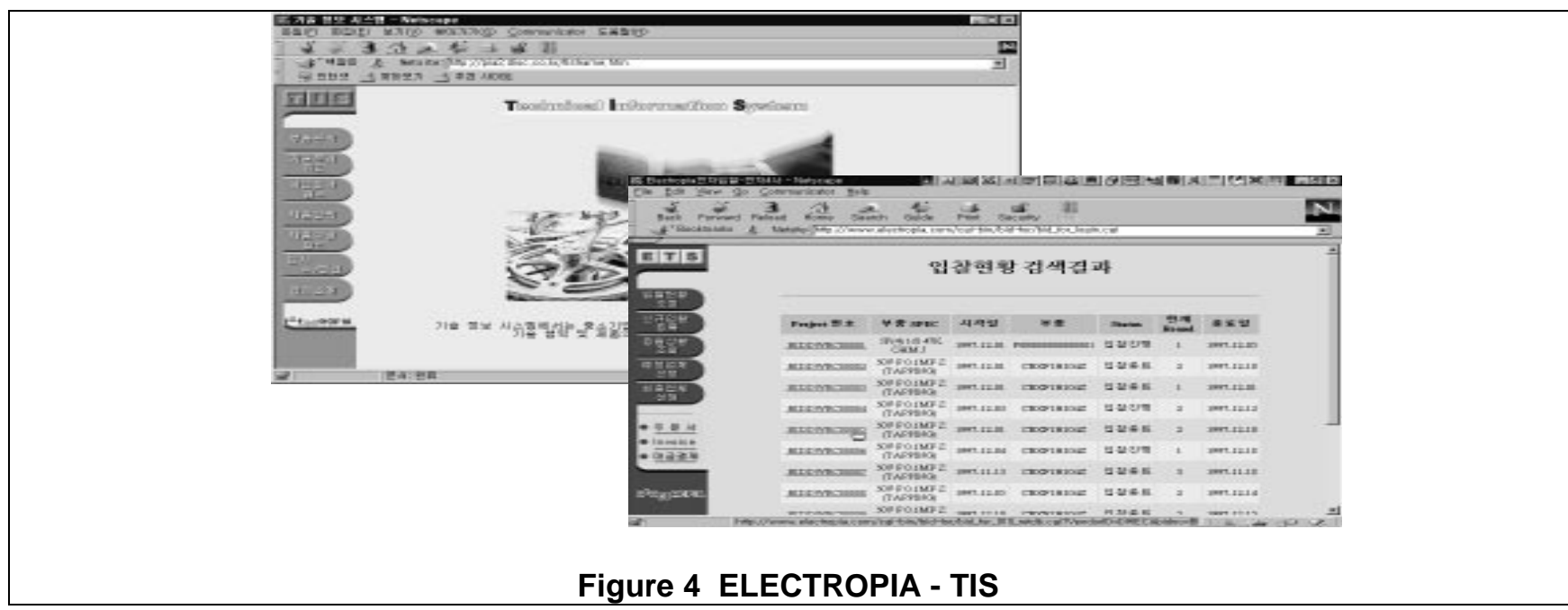

\subsection{ELECTROPIA - CSS(Customer Service System)}

name of ELECTROPIA-CSS to joint services to customers using a electronic manual among companies

We have developed the Customer Service System as the

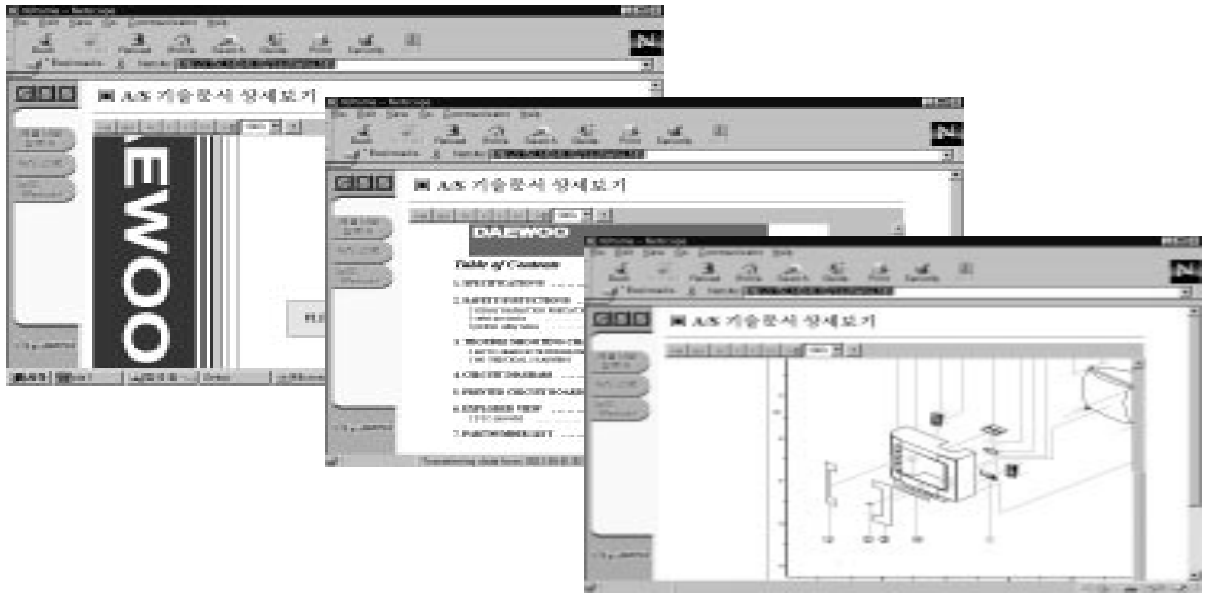

Figure 5 ELECTROPIA - CSS 


\subsection{ELECTROPIA - $\quad \operatorname{ESP}($ Electronic Shopping Plaza)}

We have developed the Electronic Shopping Plaza as the name of ELECTROPIA-ESP to provide a shopping mall to any companies whoever want to sell their products through the Internet.

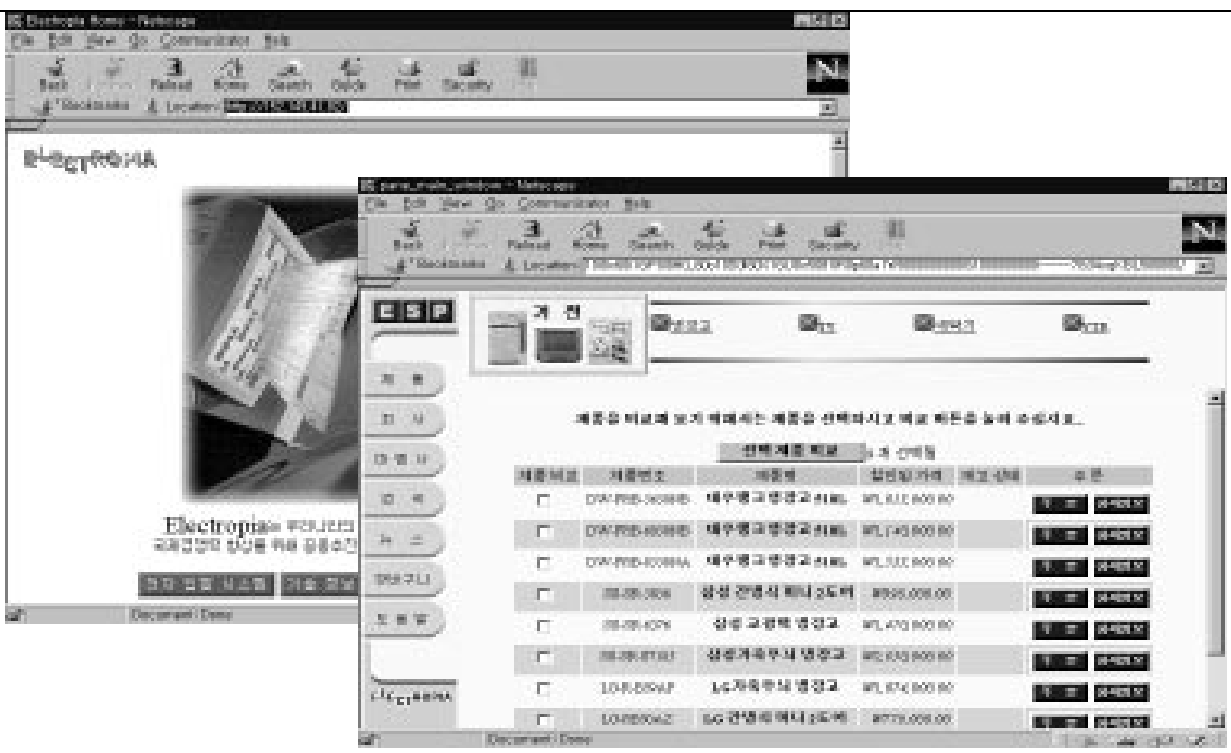

Figure 6 ELECTROPIA ESP

Electronic Shopping Plaza is developed for a company which has not enough ability to inclease their sales by themselves. With the Electronic Shopping Plaza, a customer has a chance for one stop -shopping to contact this shopping plaza which consists of most of the company who sales simmiler products.

\subsection{An architecture of the ELECTROPIA}

We work in an environment with many different hardware platforms and a myriad of software applications. When exchanging information within and between organizations, most often the file formats are incompatible and a direct transfer is not possible. As a result, the receiver must translate data coming in, and translate once again before sending data to an outside organization. Standards, or neural formats, are independent of individual software and hardware formats, but are able to carry all the information any format might contain. The user who exchanges data with another system is required to use only two programs - one to convert from his format to the standard format in order to send the message to the receiver. The receiver then, must convert the data from the neutral format to his own software format. Standards, then, become the common bridge enabling organizatons to exchange and share information more efficiently

An architecture proposed by ELECTROPIA is the foundation on which fully integrated systems are developed and implemented. It is consisted of four layers.

The first is user layer consisted of product developers, suppliers, manufactures, and customers. The second is user interface which is any web-browsers to show HTML documents and JAVA applets. The client 's machines should provide a user friendly graphical user interface. It must be able to inter-operate with the individual applications in each of the various application sets of the ELECTROPIA and has a multi-language support function. The third is application systems which have four subsystems of ELECTROPIA. The last is infrastructure which consists of standards, communication protocols, networks, and interfaces $\langle$ Figure 7$\rangle$. 


\begin{tabular}{|c|}
\hline USER \\
Product Developer, Suppliers, Manufacturers, Customers \\
\hline \hline \begin{tabular}{c|} 
USER INTERFACE \\
Web-browser(Netscape, MS-exploler)
\end{tabular} \\
\hline $\begin{array}{c}\text { APPLICATION SYSTEM } \\
\text { Electronic Tendering Syste , Technical Information Syste , } \\
\text { Customer Service System, Electronic Shopping Plaza }\end{array}$ \\
\hline \hline INFRASTRUCTURE \\
Internet,security,HTML,CGI, EDI, STEP
\end{tabular}

Figure 7 Architecture of the ELECTROPIA

\section{Future Schedule of ELECTROPIA}

The ELECTROPIA aims to establish a practical system matched to Korean needs, through the assessment of available information technology in the world-market, and through the development of data standards that users would feel no apprehension in adopting to cover the entire life cycle of their products. The ELECTROPIA is not yet completed. We have only conducted the first phase and prepare next two phases to complete this project <Table 2>.

\begin{tabular}{|c|c|}
\hline Phase & contents \\
\hline $\begin{array}{c}\text { Phase I } \\
(1997-1998)\end{array}$ & $\begin{array}{c}\text { Preparation of CALS , Basic research of CALS, CALS introduction to government, } \\
\text { companies, and school, Developing pilot system. } \rightarrow \text { done }\end{array}$ \\
\hline $\begin{array}{c}\text { Phase II } \\
(1998-2000)\end{array}$ & $\begin{array}{c}\text { Procurement,exchange technical informtion, and operating shopping mall using } \\
\text { ELECTROPIA globally by open network. }\end{array}$ \\
\hline $\begin{array}{c}\text { Phase II } \\
(2000-2003)\end{array}$ & $\begin{array}{c}\text { Intelligent shopping agent, Establishing virtual A/S center, CITIS, Electronic fund } \\
\text { transfer safely. }\end{array}$ \\
\hline
\end{tabular}

<Table 2> ELECTROPIA Plan

\section{Conclusion}

At this time, the world is moving quickly to an information-intensive society of the 21 st century as the competition of developing high technology and structuring advanced information infrastructure is intensifying. Among many related issues, Electronic Commerce and CALS has received a great deal of attention between industry and government over the last 5 to 6 years. In Korea, we are also promoting the development of Electronic Commerce, and allocating significant resources to its development. We have made a great effort to construct advanced information infrastructure within and among industries, such as intelligence networks, industry information databases, and related services.

It is clear that success in international competition depends on the degree of information intense technology, such Electronic Commerce. To cope with the rapid change of the times, we will make an epochal process with the mutual cooperation of government authorities and industries. 
First of all, the government should continue to widen the path toward the development of an information-based society. This includes, not only constructing infrastructure for telecommunication networks to connect all levels of nationwide information entities, but also developing digitized government management, and integrating digitized business processing environments in industries. Many industries find at this time that telecommunications services often are too expensive, the bandwidth is too limited, and services are unavailable or unreliable.

Efficient movements of information, either among enterprises or internal functions of an enterprise, serve as a vital mission for both public and private sector organizations who want to remain competitive in today 's advanced marketplace.

However, this requires a great deal of experience and practice in not only the development of information technology and infrastructure but also on formulation of a new digitized management model, including legal bases. Now, the Korean government is in the process of developing Electronic Commerce Laws to exist within the present framework of existing laws.

Therefore, government should embody the Electronic Commerce concept or strategy in national development programs after having a fair consensus between interested sectors such as industries, academia, and governments. In this effort, our president Kim has clearly indicated his strong commitment to establish an 'Electronic Government , to disseminate more information to the public and private sectors. In line with such thought, the government should initiate various kinds of Electronic Commerce oriented public projects to stimulate industrial Electronic Commerce including the streamlining of traditional regulations, development of standards, supporting small and medium sized industries.

Government should encourage industry self-regulation and private sector leadership where possible, and make continuous efforts to avoid undue restrictions on Electronic Commerce in order to vitalize the use of the global electronic marketplace in the private sector. In Korea, 4 System Integration companies have made a CALS/EC engine called 'ELECTROPIA' in order to promote domestic competitiveness of electronic industries. ELECTROPIA will help in promoting the international competitiveness of Korea 's industries by enhancing their technical expertise and cooperation between Korean enterprises.

The ELECTROPIA is a CALS/EC engine developed in Korea, in order to develop and procure standard public parts, support electronic commerce, and make use of Internet shopping mall and technical information owned in common. The ELECTROPIA introduced in this paper will be a standard model of implementing CALS/EC in Korea.

\section{References}

[1] Stan Dahl, A discplined approach to the identification, analysis and tracking of CALS implementation Requirements, Proceedings of the 7th international conferance of electronic commerce and enterpirse integration in Europe, 177-191, 1996.

[2] Toru Nakayama ,"Outline of MATIC Project", CICC Scope No 4, November 1995.

[3] Fairfax ECRC and the Canadian Department of National Defence, CALS REALITY-An Introduction to CALS, CALS EXPO INTERNATIONAL'95, Long Beach Convention and Entertainment Center, Long Beach, California, Dec. 5-8, 1994.

[4] R. Kalakota, A.B. Whinston, Frontiers of Electronic Commerce, Addison-Wesley Publishing, New York, 1996.

[5] J.Y.Bakos, A Strategic Analysis of Electronic Marketplaces, MIS Quartery 15, No. 3, September 1991.

[6] Gina Colarelli O 'Connor, Bob O'Keefe, Viewing the Web as a marketplace: the case of small companies, Decision Support Systems 21 (1997) 171-183.

[7] R.H. Johnston, M.Vitale, Creating competitive advantage withinter-organizational information systems, MIS Quartery, 1988, 153-165.

[8] T.W. Malone, J.Yates, R.I. Benjamin, Electronic marketsand electronic hierarchies, Communication of ACM 30(1987) 17-21.

[9] M.Lu, J.H. Song, Key decision factor for extrorganizational systems, International Journal of Information Management, 1987, 159-166 .

[10] M.Porter, Competitive Advantage: Creating and Sustaning Superior Performance, The Free Press, New York(1985).

[11] Arie Segev, Jaana Porra, Malu Roldan , Internet-based EDI strategy, Decision Support Systems 21 (1997) 157170 . 